\title{
A AÇÃO DO PERITO AVALIADOR EM IMÓVEIS URBANOS: MÉTODOS DE AVALIAÇÃO
}

\section{ARTIGO DE REVISÃO}

PESSANHA, Thayná Macêdo ${ }^{1}$

PESSANHA, Thayná Macêdo. A ação do perito avaliador em imóveis urbanos: Métodos de avaliação. Revista Científica Multidisciplinar Núcleo do Conhecimento. Ano 05, Ed. 06, Vol. 11, pp. 41-48. Junho de 2020. ISSN: 2448-0959, Link de acesso: https://www.nucleodoconhecimento.com.br/engenharia-civil/perito-avaliador

\section{RESUMO}

A ampla área de atuação da Engenharia Civil concede aos profissionais o poder de operar no ramo de maior identificação. Com evidente melhora do mercado imobiliário em 2019 e perspectiva positiva para 2020, a engenharia de avaliações tornou-se convidativa para os profissionais que têm interesse nesta área de conhecimento. $A$ Associação Brasileira de Normas e Técnicas (ABNT) apresenta a NBR 14653 (2001), sob o título de "Avaliação de bens" na qual constam os fundamentos da avaliação, que devem ser cumpridos pelos profissionais avaliadores. O presente trabalho tem 0 objetivo de discorrer sobre a ação dos engenheiros como peritos avaliadores em imóveis urbanos, atentando-se aos métodos necessários para uma análise técnica satisfatória e correta.

Palavras-chave: Engenharia de avaliações, engenheiro civil, perito avaliador.

\section{INTRODUÇÃO}

O ano de 2019 foi marcado pela reconstrução do mercado imobiliário. Com redução da taxa Selic pelo Comitê de Política Monetária (Copom) e anunciada pelo Banco

${ }^{1}$ Pós-graduada em Engenharia de Avaliações e Perícias, Graduada em Engenharia Civil. 
Central (BC), chegando ao menor valor Selic da história. Conforme divulgado pelo Banco Central, denomina-se Selic a taxa básica de juros da economia. É o principal mecanismo de política monetária utilizado pelo Banco Central para controlar a inflação. Ela influencia todas as taxas de juros do país, como as de empréstimos, financiamentos e aplicações financeiras. Essa redução mostra consequência nos financiamentos, com dedução em seus custos. Os números favoráveis dão maior segurança tanto para quem quer adquirir a casa própria, quanto para quem quer investir em imóveis, visto que se trata de um bem de consumo que proporciona um amparo econômico, sendo uma forma de reserva e apropriação de capitais, além de um meio de benefício financeiro com rendas locatícias e de vendas.

Determinar tecnicamente o valor de um bem imóvel, é importante para a tomada de decisão em vários segmentos da sociedade. É papel da Engenharia de Avaliações coletar, tratar e analisar dados e estimar modelos que expliquem satisfatoriamente, a oscilação encontrada nos preços, no mercado estudado em questão.

O CREA (2013) especifica que apenas os profissionais de engenharia têm competência técnica necessária para elaborar laudos das avaliações imobiliárias, atendendo à prescrição da Associação Brasileira de Normas e conforme o Código de Defesa do Consumidor, que proíbe qualquer tipo de comercialização de produto ou serviço em desacordo com as normas técnicas. Deste modo, os laudos emitidos pelos avaliadores devem estar em concordância com a NBR 14653-2 da ABNT e com o artigo 39 do CDC.

\section{DESENVOLVIMENTO}

\section{A AÇÃO DO PERITO AVALIADOR EM IMÓVEIS URBANOS: MÉTODOS DE AVALIAÇÃO}

A área de avaliação de imóveis foi estabelecida a partir a abolição do regime de sesmarias, com a promulgação da Lei de Terras № 601/1850, que estabeleceu a compra como a única forma de obter terras públicas, regulamentando a propriedade privada. Mas só recebeu visibilidade em meados da década de 30 , quando os 
primeiros trabalhos sobre o assunto foram publicados em decorrência do crescente urbanismo. Em 1977, a Associação Brasileira de Normas Técnicas (ABNT) elaborou uma norma para a avaliação de imóveis urbanos, a NBR 5676, que se tornou posteriormente a NBR 14653.

O IBAPE (1994) define perito como um profissional legalmente habilitado, especialista, convocado para realizar uma perícia e define perícia como uma atividade concernente a exame realizado por profissional especialista, legalmente habilitado, com intenção de esclarecer determinado fato, apurar as causas ocasionadoras do mesmo, ou o estado, estimação daquele que é objeto de litígio ou de processo.

Abunahman (2008) descreve a avaliação de imóveis como a ponderação de um ou mais aspectos dessa propriedade, tanto econômicos quanto físicos para estipular o valor ou a situação de um bem imóvel.

A ABNT (2001) declara que o Engenheiro de Avaliações deve conduzir uma vistoria que prescindirá as avaliações, com o propósito de conhecer e caracterizar o bem analisado e sua adequação ao seu segmento de mercado, registrando-se suas características físicas, de utilização e outros aspectos relevantes à formação do valor. Esta descrição pode ser acrescentada com plantas, fotografias, desenhos e outros documentos.

A ABNT (2001), através da NBR 14653-1, especifica os principais métodos para identificar o valor de um bem, de seus frutos e direitos.

\section{MÉTODO COMPARATIVO DIRETO DE DADOS DE MERCADO}

Neste método, aponta-se o valor de mercado de um bem por meio do tratamento técnico dos atributos dos elementos análogos, contribuintes da amostra. O valor é determinado através da comparação entre dados de mercado relativos às propriedades de características semelhantes ao mesmo (ABNT, 2001).

É importante destacar que não existem duas propriedades idênticas, o que dificulta a utilização deste método. Fatores como a metragem do terreno, da área construída, a 
localização do bem, a qualidade do material, do acabamento, o estado de manutenção e conservação tornam cada imóvel único e singular.

Este método deve ser usado preferencialmente em avaliações de propriedades. É realizado através de:

a) cálculo do valor da propriedade avalianda;

b) caracterização da propriedade avalianda;

c) pesquisa de dados relativos à propriedade semelhantes à propriedade avalianda.

Um terreno é único. Mesmo em loteamentos com terrenos muito semelhantes, características de vizinhança em breve Ihe conferirão atributos de diferenciação. Além de singulares, os terrenos são irreprodutíveis e inamovíveis (MOREIRA, 1994), mas alguns fatores influenciam no seu valor:

a) região:

- a vizinhança pode interferir positiva ou negativamente. Instalações com ruídos demasiados nas adjacências, com emissão de gases poluentes tendem a desvalorizar o valor do imóvel, a proximidade de comércios, mercado de trabalho, transportes coletivos e o seu potencial de utilização tendem a valorizar o seu valor;

b) logradouros públicos:

- ruas estreitas, com dificuldade de circular e estacionar e rampas muito íngremes tendem a desvalorizar o valor. Ruas com largura média, com rede de esgoto, de água, pavimentação adequada e boa iluminação tendem a valorizar;

c) atributos físicos do imóvel:

- a área, o relevo, o sub-solo, a profundidade, a natureza da superfície são fatores que também favorecem ou desfavorecem o valor. 
Na etapa do planejamento da pesquisa, compõem-se uma amostra da qual se coletará dados de mercado de propriedades com características, tanto quanto possível, semelhantes às do avaliando, usando-se toda a evidência disponível. Inicia-se pela caracterização e delimitação do mercado em análise, com a colaboração de conceitos existentes ou cenários oriundos de experiências contraídas pelo profissional avaliador (ABNT, 2004).

Na estrutura da pesquisa são selecionadas as variáveis, necessárias para demonstrar a formação de valor e estabelecidas as supostas relações entre si e com a variável dependente, ou seja, o valor do imóvel. São elas: a variável dependente (investigação no mercado em relação à sua atuação e às formas de expressão dos preços) e as variáveis independentes (características econômica, física e de localização).

A coleta de dados é uma importante etapa do processo. Para que seja alcançado um resultado válido, deve conter esclarecimentos sobre as transações feitas com imóveis em condições semelhantes.

O avaliador deve atentar-se para escolha dos elementos utilizados como referência para formar a amostra, tendo em vista as particularidades de cada unidade, como: estado de conservação, tipo de construção, localização, fatores depreciativos, idade, qualidade, região, entre outros.

Dantas (1998) enfatiza a necessidade de homogeneizar os valores no que se refere ao imóvel avaliando para torná-lo compatível com as outras informações pesquisadas. A ABNT (2004) apresenta dois procedimentos para o tratamento dos dados coletados:

a) tratamento por fatores:

- os elementos da amostra são alterados por fatores ou coeficientes corretivos e, posteriormente, os resultados homogeneizados são submetidos à análise estatística (GONZÁLEZ, 1997). Entretanto, a adoção dos fatores confere subjetividade à avaliação, o que restringe este método;

b) tratamento científico: 
- a homogeneização dos valores é feita pela adoção de modelos resultantes de métodos científicos, baseados essencialmente na inferência estatística (DANTAS, 1998). Todavia, qualquer modelo é sempre uma simplificação do mercado, uma vez que não considera todas as suas informações.

\section{MÉTODO INVOLUTIVO}

Segundo a ABNT (2001), o custo do bem avaliado é indicado pela eficiência de sua aplicação. Através de uma suposta edificação compatível com as características do bem e com a situação do mercado no qual está inserido, forma-se um modelo de projeto de viabilidade técnico-econômico.

A avaliação é realizada em função do aproveitamento potencial, identificando o melhor uso, tanto em quantidade quanto em qualidade. Nela, o avaliador produz um anteprojeto dos lotes ou construções (considerando as utilizações permitidas no plano diretor da região), realiza o orçamento, pesquisa de dados de mercado, afere a viabilidade e as despesas prováveis, como os lucros de venda, custos com corretagem, alugueis e taxas.

Este método é empregado em casos onde não encontram dados de transações de imóveis similares.

\section{MÉTODO EVOLUTIVO}

De acordo com a ABNT (2001), no método evolutivo, se identifica o valor do bem por meio do somatório dos valores de seus constituintes. Deve-se dar importância especial ao fator de comercialização caso o objetivo seja a identificação do valor de mercado.

Em locais onde a urbanização é concentrada, o valor de um terreno pode ser obtido através da diferença entre o valor do terreno somado à benfeitoria, identificado através da pesquisa de mercado, e o valor individual da benfeitoria, obtido através do método da quantificação de custos. 
Este método é benéfico para avaliações de terrenos situados em áreas com grande concentração de urbanização, que tem pouca ou insuficiente informação de terrenos vazios mas que existem terrenos com construções. Obtém-se o valor do terreno a partir do valor total do imóvel, deduzindo deste os valores das construções existentes. Pode ser aplicado também quando a finalidade é a apuração do valor das construções, encontrado ao subtrair o valor do terreno pelo valor inteiro do empreendimento.

\section{MÉTODO DA CAPITALIZAÇÃO DE RENDA}

O método identifica o valor do bem baseando-se na capitalização presente da sua renda líquida prevista, atentando-se para os cenários que são viáveis (ABNT, 2001).

Fundamenta-se na hipótese de que a valorização de um imóvel se dá pela arrecadação que pode proporcionar ao proprietário. Tem-se que: um imóvel com alto valor de mercado terá um alto valor de aluguel, deste modo, o total de renda que este imóvel pode proporcionar quando alugado durante sua vida útil é interpretado como um indicativo de seu valor.

Este método tem o objetivo de obter informações sobre os valores quando não existem transações disponíveis no momento ou quando os imóveis são distintos (como hotéis, hospitais e outros imóveis).

\section{CONSIDERAÇÕES FINAIS}

No que se refere aos métodos para avaliação de imóveis urbanos, a NBR 14653-1 da Associação Brasileira de Normas Técnicas, orienta a utilização do método comparativo de dados de mercado sempre que possível. Entretanto, imóveis singulares prejudicam na procura de imóveis semelhantes no mercado, já que encontrar dados similares aos do bem avaliado, como as dimensões, topografia, localização ou período de transação não é simples, sendo necessário a realização de uma homogeneização para viabilizar a comparação.

Fiker (2011) também dá ênfase ao método comparativo de dados de mercado, citando-o como o mais recomendado. Mas esclarece que o profissional deve recorrer 
a fontes de informações, mas com cautela quanto a veracidade das informações encontradas, visto que compromissos de compra e venda particulares costumam refletir melhor as condições prováveis de preços reais de transações do que escrituras definitivas. Isso porque, nos compromissos, comprador e vendedor se cercam de cuidados para evitar inadimplências contratuais, mas nas escrituras definitivas pode ser conveniente par ambos, por razões tributárias, que o imóvel fique registrado por preço superior ou inferior ao legítimo.

O processo de avaliação é minucioso. Suas etapas são bem definidas, mas podem ser aplicadas com algumas variações em determinados casos. Quando não é possível aplicar o método comparativo, é preciso aplicar um dos outros três métodos disponíveis: método da capitalização de renda, método evolutivo ou método involutivo. A seleção do método deve ser justificada conforme cada situação e respeitar a norma técnica publicada pela ABNT para uma avaliação precisa e correta.

\section{REFERÊNCIAS}

ABNT. ASSOCIAÇÃO BRASILEIRA DE NORMAS TÉCNICAS. NBR 14653-1: Avaliação de bens Parte 1: Procedimentos Gerais. Rio de Janeiro, 2001

ABNT. ASSOCIAÇÃO BRASILEIRA DE NORMAS TÉCNICAS. NBR 14653-2: Avaliação de Bens Parte 2: Imóveis Urbanos. Rio de Janeiro, 2004

ABNT. ASSOCIAÇÃO BRASILEIRA DE NORMAS TÉCNICAS. NBR 13752: Perícias de Engenharia na Construção Civil. Rio de Janeiro, 1996

ABUNAHMAN, Sérgio Antonio. Engenharia Legal e de Avaliações: 4. ed. São Paulo: PINI, 2008

BRASIL. Lei n. 8078, de 11 de setembro de 1990. Código de Defesa do Consumidor, Brasília, DF, set 1990

CONSELHO REGIONAL DE ENGENHARIA DE AGRONOMIA. Manual de Fiscalização de Engenharia de Avaliações. Curitiba, 2013 
DANTAS, Rubens Alves. Engenharia de Avaliações: uma introdução à metodologia científica. São Paulo: Pini,1998

FIKER, José. Manual de Avaliações e Perícias em Imóveis Urbanos: 5. ed. São Paulo: Oficina de Textos, 2011

GONZÁLEZ, Marco Aurélio Stumpf. A Engenharia de Avaliações na Visão Inferencial. São Leopoldo: Unisinos, 1997

GOVERNO DO BRASIL. Banco Central do Brasil, 2019. Disponível em: <https://www.bcb.gov.br/controleinflacao/taxaselic> Acesso em: 20 nov. de 2019.

IBAPE. INSTITUTO BRASILEIRO DE AVALIAÇÕES E PERÍCIAS. Glossário de Terminologia Básica Aplicável à Engenharia de Avaliações e Perícias. São Paulo, 1994

MOREIRA, Alberto Lélio. Princípios de engenharia de avaliações. São Paulo: Pini, 1994

Enviado: Março, 2020.

Aprovado: Junho, 2020. 